\title{
Glutamate Clearance Is Locally Modulated by Presynaptic Neuronal Activity in the Cerebral Cortex
}

\author{
Moritz Armbruster, ${ }^{1}{ }^{-E}$ Elizabeth Hanson, ${ }^{1,2}$ and ${ }^{-C h r i s ~ G . ~ D u l l a ~}{ }^{1,2}$ \\ ${ }^{1}$ Department of Neuroscience, Tufts University School of Medicine, Boston, Massachusetts 02111, and ${ }^{2}$ Neuroscience Program, Tufts Sackler School of \\ Biomedical Sciences, Boston, Massachusetts 02111
}

Excitatory amino acid transporters (EAATs) are abundantly expressed by astrocytes, rapidly remove glutamate from the extracellular environment, and restrict the temporal and spatial extent of glutamate signaling. Studies probing EAAT function suggest that their capacity to remove glutamate is large and does not saturate, even with substantial glutamate challenges. In contrast, we report that neuronal activity rapidly and reversibly modulates EAAT-dependent glutamate transport. To date, no physiological manipulation has shown changes in functional glutamate uptake in a nonpathological state. Using iGluSnFr-based glutamate imaging and electrophysiology in the adult mouse cortex, we show that glutamate uptake is slowed up to threefold following bursts of neuronal activity. The slowing of glutamate uptake depends on the frequency and duration of presynaptic neuronal activity but is independent of the amount of glutamate released. The modulation of glutamate uptake is brief, returning to normal within $50 \mathrm{~ms}$ after stimulation ceases. Interestingly, the slowing of glutamate uptake is specific to activated synapses, even within the domain of an individual astrocyte. Activity-induced slowing of glutamate uptake, and the increased persistence of glutamate in the extracellular space, is reflected by increased decay times of neuronal NR2A-mediated NMDA currents. These results show that astrocytic clearance of extracellular glutamate is slowed in a temporally and spatially specific manner following bursts of neuronal activity $\geq 30 \mathrm{~Hz}$ and that these changes affect the neuronal response to released glutamate. This suggests a previously unreported form of neuron-astrocyte interaction.

Key words: activity; astrocyte; cortex; glutamate; glutamate uptake

\section{Significance Statement}

We report the first fast, physiological modulation of astrocyte glutamate clearance kinetics. We show that presynaptic activity in the cerebral cortex increases the persistence of glutamate in the extracellular space by slowing its clearance by astrocytes. Because of abundant EAAT expression, glutamate clearance from the extracellular space has been thought to have invariant kinetics. While multiple studies report experimental manipulations resulting in altered EAAT expression, our findings show that astrocytic glutamate uptake is dynamic on a fast time-scale. This shows rapid plasticity of glutamate clearance, which locally modulates synaptic signaling in the cortex. As astrocytic glutamate uptake is a fundamental and essential mechanism for neurotransmission, this work has implications for neurotransmission, extrasynaptic receptor activation, and synaptic plasticity.

\section{Introduction}

Efficacious glutamate uptake following neuronal activity shapes extracellular glutamate transients (Clements et al., 1992; Dia-

\footnotetext{
Received June 28, 2016; revised Aug. 12, 2016; accepted Aug. 18, 2016.

Author contributions: M.A. and C.G.D. designed research; M.A. and E.H. performed research; M.A. and E.H. analyzed data; M.A. and C.G.D. wrote the paper.

This work was supported by National Institute of Neurological Disorders and Stroke R01 NS076885 to C.G.D., National Institute of Neurological Disorders and Stroke Synapse Neurobiology Training Grant NINDS T32-NS061764 to E.H., Tufts Center for Neuroscience Research P30 NS047243, and The Epilepsy Foundation to M.A. We thank Dr. Kevin Staley, Dr. Paul Rosenberg, Dr. Jeff Diamond, and Jennifer Shih for helpful discussions.

The authors declare no competing financial interests.

Correspondence should be addressed to Dr. Chris G. Dulla, Department of Neuroscience, Tufts University, School of Medicine, 136 Harrison Avenue, Boston, MA 02111. E-mail: Chris.Dulla@Tufts.edu.

DOI:10.1523/JNEUROSCI.2066-16.2016

Copyright $\odot 2016$ the authors $\quad 0270-6474 / 16 / 3610404-12 \$ 15.00 / 0$
}

mond and Jahr, 1997; Bergles et al., 1999; Marvin et al., 2013), constrains extrasynaptic NMDA receptor activation (ArnthJensen et al., 2002; Scimemi et al., 2009), and prevents seizures (Tanaka et al., 1997). The majority of glutamate uptake occurs via excitatory amino acid transporters (EAATs) expressed by astrocytes (GLT-1 and GLAST) and is rapid, ensuring temporally brief and spatially restricted glutamate neurotransmission (Bergles and Jahr, 1997; Diamond and Jahr, 2000; Danbolt, 2001; Diamond, 2005). Astrocyte processes contact the majority of, and even envelope some synapses in, the neocortex (Spacek, 1985; Jones and Greenough, 1996). EAATs are heavily expressed at these processes (Rothstein et al., 1994; Chaudhry et al., 1995; Minelli et al., 2001) and provide rapid removal of synaptically released glutamate. 
The kinetics of glutamate clearance are independent of the magnitude of glutamate challenge in vitro (Diamond and Jahr, 2000; Diamond, 2005; Armbruster et al., 2014; Hanson et al., 2015) and in vivo (Ohta et al., 1994; Svensson et al., 1994), consistent with the robust expression of EAATs (Lehre and Danbolt, 1998) and the strong ionic driving force for transport (Levy et al., 1998). This suggests that astrocytic EAATs represent a sink for extracellular glutamate that is rarely saturated. Having a system that provides constant and invariant removal of glutamate is neuroprotective and helps provide robust synaptic specificity. A growing number of studies suggest, however, that astrocytic glutamate uptake may be more dynamic than previously appreciated. For example, extracellular glutamate dynamics are affected by GLT-1 surface diffusion (Murphy-Royal et al., 2015) and astrocyte cytoarchitecture (Pannasch et al., 2014). Here, we show that presynaptic activity alone can rapidly and reversibly slow glutamate clearance, through modulation of EAAT function.

To perform this study, we used an imaging-based approach to assay glutamate dynamics in the extracellular space (Borghuis et al., 2013; Marvin et al., 2013). Viral expression of the intensitybased glutamate-sensing fluorescent reporter (iGluSnFr) allows imaging of iGluSnFr signals (iGS), which enables measurement of extracellular glutamate clearance (Parsons et al., 2016). iGluSnFr is an extracellular membrane tethered sensor, which can be expressed with cell type specificity, traffics throughout the plasma membrane, and allows sampling of the glutamate environment in the extracellular space. In addition, we used an established electrophysiological method to record glutamate transporter currents (GTCs) (Bergles and Jahr, 1997; Diamond and Jahr, 2000; Diamond, 2005), which allows quantification of glutamate uptake by individual astrocytes. GTCs and iGS are two distinct assays, which provide measures of glutamate uptake and extracellular glutamate levels, respectively. Using both techniques, we explored the relationship between presynaptic activity, extracellular glutamate accumulation, and glutamate clearance. Our results show that glutamate clearance is slowed by presynaptic activity $\geq 30 \mathrm{~Hz}$ and is independent of the amount of glutamate released. The activity-dependent slowing we report recovers rapidly $(<50 \mathrm{~ms})$ and occurs in an input-specific manner, even within the domain of a single astrocyte. The mechanism of this slowing has yet to be identified, but these results demonstrate a novel linkage between presynaptic activity and astrocyte function that locally and rapidly modulates glutamate clearance. Last, this slowing of uptake, resulting in increased glutamate persistence in the extracellular space, is reflected in prolonged postsynaptic NR2A-specific NMDA receptor currents. This novel finding suggests that physiological activity can dynamically modulate glutamate clearance and, thus, requires a revision of how we think about glutamate uptake.

\section{Materials and Methods}

All protocols were approved by the Tufts Institutional Animal Care and Use Committee.

Adeno-associated virus injection. C57BL/6 male and female mice (approximately equal ratio of sex) were stereotaxtically injected between 30 and $37 \mathrm{~d}$ postnatal with either GFAP-iGluSnFr or hSyn-iGluSnFr (University of Pennsylvania Vector Core; catalog \#AV-5-PV2723, AV-5PV2914) in a single hemisphere with 3 injections sites (coordinates): $(1.25,1.25,0.5),(1.25,2.25,0.5)$, and $(1.25,3.25,0.5)(\lambda+x,+y,-z)$ $\mathrm{mm}$. Mice were anesthetized with isoflurane for surgery, reporter viruses were injected with $1 \mu \mathrm{l}$ per site $(0.1-0.2 \mu \mathrm{l} / \mathrm{min})$ at $4.5 \mathrm{E} 9$ gene copies. Mice were used for immunofluorescence or acute slice preparations 14-28 d after injection. Mice were housed in 12/12 light/dark cycles following surgeries.
Preparation of acute brain slices. Cortical brain slices, $400 \mu \mathrm{m}$ thickness, were prepared from control or iGluSnFr-infected C57/B6 mice (Armbruster et al., 2014). Mice were anesthetized with isoflurane, decapitated, and the brains were rapidly removed and placed in ice-cold slicing solution equilibrated with $95 \% \mathrm{O}_{2}: 5 \% \mathrm{CO}_{2}$ (in mM) as follows: $2.5 \mathrm{KCl}$, $1.25 \mathrm{NaH}_{2} \mathrm{PO}_{4}, 10 \mathrm{MgSO}_{4}, 0.5 \mathrm{CaCl}_{2}, 11$ glucose, 234 sucrose, and 26 $\mathrm{NaHCO}_{3}$. The brain was glued to a Vibratome VT1200S (Leica), and slices were cut in a coronal orientation. Slices were then placed into a recovery chamber containing aCSF (in $\mathrm{mm}$ ) as follows: $126 \mathrm{NaCl}, 2.5$ $\mathrm{KCl}, 1.25 \mathrm{NaH}_{2} \mathrm{PO}_{4}, 1 \mathrm{MgSO}_{4}, 2 \mathrm{CaCl}_{2}, 10$ glucose, and $26 \mathrm{NaHCO}_{3}$ (equilibrated with $95 \% \mathrm{O}_{2}: 5 \% \mathrm{CO}_{2}$ ) then equilibrated in aCSF at $32^{\circ} \mathrm{C}$ for $1 \mathrm{~h}$. Slices used for astrocyte electrophysiology were loaded with sulforhodamine $101(\mathrm{SR}-101,0.5 \mu \mathrm{M})$ in aCSF for $5 \mathrm{~min}$ at $32^{\circ} \mathrm{C}$ before equilibration (Nimmerjahn et al., 2004). Slices were allowed to return to room temperature and used for live imaging or electrophysiology.

Live imaging. iGluSnFr slices were placed into a submersion chamber (Siskiyou), held in place with small gold wires, and perfused with aCSF containing $20 \mu \mathrm{M}$ DNQX (antagonist of AMPA receptors), and $10 \mu \mathrm{M}$ 3-(2-carboxypiperazin-4-yl)propyl-1-phosphonic acid (CPP, antagonist of NMDA receptors), equilibrated with $95 \% \mathrm{O}_{2}: 5 \% \mathrm{CO}_{2}$ and circulated at $2 \mathrm{ml} / \mathrm{min}$ at $34^{\circ} \mathrm{C}$. A tungsten concentric bipolar stimulating electrode (FHC) was placed in the deep cortical layers, and the upper cortical layers were imaged with a $60 \times$ water-immersion objective (LUMPLANFL, Olympus) on an Olympus BX51 microscope. For two-stimulator experiments, a second identical tungsten stimulating electrode was placed in the upper cortical layers $\sim 450 \mu \mathrm{m}$ from the site of recording. The $100 \mu \mathrm{s}$ stimulus pulses were generated every $30 \mathrm{~s}$ through stimulus isolators ISO-Flex (A.M.P.I.) or S-88/SIU-5 (Grass Instruments). Stimulus intensity was set at $2 \times$ the resolvable threshold stimulation, and no significant difference was observed in the threshold level between the GFAPiGluSnFr and hSyn-iGluSnFr reporter (log-corrected two-sample $t$ test, $p>0.5, N=21,17$ slices, GFAP and hSyn, respectively). Imaging was performed using a Zyla (Andor) camera imaging $2048 \times 2048$ with $4 \times$ binning, 16 bit digitization, $10 \mathrm{~ms}$ rolling shutter mode for $100 \mathrm{~Hz}$ temporal resolution, illuminated by a $480 \mathrm{~nm}$ LED (Thorlabs), using the endow-GFP filter cube (Chroma) and controlled by MicroManager (Edelstein et al., 2014). Following control runs, slices were treated with $300 \mu \mathrm{M}$ dihydrokainate (DHK, antagonist of GLT-1 glutamate transporters), $1 \mu \mathrm{M}(3 \mathrm{~S})$-3-[[3-[[4-(trifluoromethyl)benzoyl] amino]phenyl], ethoxy]-L-aspartic acid (TFB-TBOA, broad-spectrum inhibitor of glutamate transport), $4 \mu \mathrm{M}$ N6-cyclopentyladenosine (CPA, $\mathrm{A}_{1}$-receptor agonist), $0.3 \mu \mathrm{M}$ 8-cyclopentyl-1,3-dipropylxanthine (DPCPX, $\mathrm{A}_{1}$ receptor antagonist), or HEPES-bicarb aCSF containing (in $\mathrm{mM}$ ) the following: $111 \mathrm{NaCl}, 2.5 \mathrm{KCl}, 1.25 \mathrm{NaH}_{2} \mathrm{PO}_{4}, 1 \mathrm{MgSO}_{4}, 2 \mathrm{CaCl}_{2}, 10$ glucose, $20 \mathrm{HEPES}, 35 \mathrm{NaHCO}_{3}$ (MacGregor et al., 2001). Drugs were washed on for 5-10 min before recommencing imaging and did not show a systematic change in the fluorescent baseline.

Glutamate transporter currents. Glutamate transporter currents were recorded similar to previous studies (Diamond, 2005; Armbruster et al., 2014; Hanson et al., 2015). Briefly, whole-cell patch-clamp recordings were made in an identical setup to the live-cell imaging, with aCSF containing $200 \mu \mathrm{M} \mathrm{BaCl}{ }_{2}$ to block astrocyte $\mathrm{K}^{+}$conductances (Ransom and Sontheimer, 1995; Afzalov et al., 2013). Astrocytes were identified by morphology (small, round cell bodies), membrane properties, and SR101 labeling (Nimmerjahn et al., 2004) as imaged with a Cy3 filter cube (excitation 560/40 nm, emission 630/75 nm, Chroma). Astrocyte internal solution contained the following (in $\mathrm{mm}$ ): 120 potassium gluconate, 20 HEPES, 10 EGTA, $2 \mathrm{MgATP}$, and $0.2 \mathrm{NaGTP}$. The $4-12 \mathrm{M} \Omega$ borosilicate pipettes were used to establish whole-cell patch-clamp recordings using a Multiclamp 700B patch-clamp amplifier (Molecular Devices), sampled at $10 \mathrm{kHz}$ using pClamp software. Once a whole-cell recording was established, cells were confirmed as astrocytes based on their passive membrane properties, low membrane resistance, and hyperpolarized resting membrane potential. Slices were perfused with aCSF containing $20 \mu \mathrm{M}$ DNQX, and $10 \mu \mathrm{M}$ CPP, which was oxygenated and circulated at 2 $\mathrm{ml} / \mathrm{min}$ at $34^{\circ} \mathrm{C}$. GTCs were activated by electrical stimulation $(100 \mu \mathrm{s})$. In voltage-clamp mode, whole-cell patch-clamped astrocytes were maintained at $-80 \mathrm{mV}$. To record GTCs, each sweep contained a $+5 \mathrm{mV}, 20$ $\mathrm{ms}$ voltage step, followed $40 \mathrm{~ms}$ later by 1 or 10 stimuli at $100 \mathrm{~Hz}$. The 5 
$\mu \mathrm{M}$ TFB-TBOA was washed and used to isolate the specific glutamate transport component of the current. All synaptic GTCs presented and analyzed are TBOA subtractions.

NR2A-NMDA receptor EPSC current recording. NMDA receptor EPSCs were recorded similar to previous studies (Hanson et al., 2015). Briefly, whole-cell patch-clamp recordings were made in an identical setup to the live-cell imaging, with aCSF containing gabazine $(10 \mu \mathrm{M})$, DNQX $(20 \mu \mathrm{M})$, ifenprodil $(5 \mu \mathrm{M})$, and D-serine (30 $\mu \mathrm{M})$. Neurons identified by morphology in layer II/III of the cortex were whole-cell patchclamped using 2-5 $\mathrm{m} \Omega$ borosilicate glass electrodes containing the following (in mM): 120 D-gluconic acid, $120 \mathrm{CsOH}, 10 \mathrm{HEPES}, 10 \mathrm{EGTA}$, $0.5 \mathrm{CaCl}_{2}, 20 \mathrm{TEA}, 2 \mathrm{MgATP}$, and $0.2 \mathrm{NaGTP}$. In voltage-clamp mode, neurons were held at $+40 \mathrm{mV}$ to relieve the $\mathrm{Mg}^{2+}$ block of the NMDA receptors and allowed to stabilize. NMDA currents were then evoked identically to the glutamate transporter currents above, and were blocked by wash of APV $(50 \mu \mathrm{M})$. Access resistance was monitored throughout the experiment, and cells with more than a $25 \%$ change were excluded from analysis.

Immunofluorescence. Fixed mouse brains were prepared by transcardial perfusion with $4 \%$ PFA. Fixed brains were sectioned at $30 \mu \mathrm{m}$ using a Thermo Fisher Microm HM 525 cryostat. Brain sections were blocked using blocking buffer (5\% normal goat serum, $1 \%$ BSA, in PBS) for $1 \mathrm{~h}$ at room temperature. NEUN (1:500, MAB377B, Millipore), GFP (1:500, ab13970 Abcam), and glutamine synthase (1:500, MAB302, Millipore) antibodies were diluted in PBS with 2\% Triton X-100 and 5\% blocking buffer. Cortical sections were incubated with diluted primary antibodies overnight at $4^{\circ} \mathrm{C}$. Secondary antibodies (goat anti-rabbit Cy3, goat-anti chicken FITC, Jackson ImmunoResearch Laboratories) were diluted 1:500 in PBS with 5\% blocking buffer and added to cortical sections for $2 \mathrm{~h}$ at room temperature. Slices were imaged with a Nikon A1R confocal microscope. Slices from 3 mice were stained for all experiments, with 2-4 slices per mouse visualized.

Analysis. Analysis was performed using MATLAB (The MathWorks) and Origin (Originlab). For live-imaging studies, the center $256 \times 256$ pixels of the $512 \times 512$ pixel images were isolated and averaged providing a readout of glutamate dynamics across a patch of cortex. Two to six repeated runs of identical stimulation were subsequently averaged together. Based on photobleaching decay constants determined through unstimulated runs, the 100 prestimulus frames were fit with a biexponential bleaching function and used to establish a photobleaching correction for each run. The poststimulus decays were fit at the end of the stimulus or with a 1 frame off set (single stimulus) with a monoexponential decay. Decay constants and peak fluorescence signals were not sensitive to increased aCSF pH buffering capacity by the inclusion of $20 \mathrm{~mm}$ HEPES buffer, suggesting that extracellular alkalization did not change the peak fluorescence (paired Wilcoxon signed rank test, $p>$ 0.43 ) or decay time constant (paired $t$ test, $p>0.28, N=6$ slices). Total amount of glutamate released was measured after blocking glutamate transporters with the inhibitor TFB-TBOA and is defined as the peak $\Delta \mathrm{F} / \mathrm{F}$ for 1 , 60 , and $100 \mathrm{~Hz}$, and as the cumulative response to each stimuli for 10 and 30 $\mathrm{Hz}$ to account for slow clearance of glutamate in TFB-TBOA.

For astrocyte synaptic transporter current recordings, 2-8 sweeps were averaged and normalized to a $+5 \mathrm{mV}$ voltage step to correct for changes in access resistance. TFB-TBOA sweeps were subtracted from control to isolate the glutamate transporter currents. The decay of the glutamate transporter current was then fit with a mono-exponential decay function to quantify the glutamate uptake kinetic. For NMDA EPSCs, 12-18 sweeps were averaged. The decay of the NMDA EPSC was then fit with a mono-exponential decay function to quantify the glutamate transient.

Statistics. Normality was tested using the Shapiro-Wilk test $(\alpha=0.05)$. Hypotheses were tested using paired or two sample $t$ tests, nonparametric Wilcox-Signed rank test, or nonparametric Mann-Whitney test as appropriate. Grubb's test for outliers was used to exclude a single slice from Figure $1 C(p<0.05)$. Samples sizes (slices/cells) are listed for each experiment in the figure labels or text, all experiments are from $\geq 3$ animals. Significance of multiple comparisons was tested using the Holm-Bonferroni method. Error bars indicate SEM.
Drugs and reagents. Unless otherwise noted, all salts and glucose were obtained from Sigma-Aldrich. Drugs used in the study and their concentration: APV (NMDA antagonist, $50 \mu \mathrm{M}$, Tocris Bioscience) (Evans et al., 1982); CPA (A $\mathrm{A}_{1}$-receptor agonist, $4 \mu \mathrm{M}$, Sigma) (Dunwiddie and Fredholm, 1984); CPP (NMDA antagonist, $10 \mu \mathrm{M}$, Abcam, Tocris Bioscience) (Davies et al., 1986); DHK ((2S,3S,4R)-3-(Carboxymethyl)4-isopropylpyrrolidine-2-carboxylic acid, GLT-1 antagonist, $300 \mu \mathrm{M}$, Abcam) (Arriza et al., 1994); DNQX (AMPA antagonist, $20 \mu \mathrm{M}$, Sigma) (Honoré et al., 1988); DPCPX ( $\mathrm{A}_{1}$-receptor antagonist, $0.3 \mu \mathrm{M}$, Sigma) (Lee and Reddington, 1986); D-serine (NMDA coagonist, $30 \mu \mathrm{M}$, Sigma) (Le Meur et al., 2007); gabazine (6-imino-3-(4-methoxyphenyl)$1(6 H)$-pyridazinebutanoic acid hydrobromide, $\mathrm{GABA}_{\mathrm{A}}$ antagonist, 10 $\mu \mathrm{M}$, Tocris Bioscience) (Heaulme et al., 1986); Ifenprodil $\left(\left(1 S^{\star}, 2 S^{\star}\right)\right.$ threo-2-(4-Benzylpiperidino)-1-(4-hydroxyphenyl)-1-propanol hemitartrate; NR2B antagonist, $5 \mu \mathrm{M}$, Tocris Bioscience) (Williams, 1993); TFB-TBOA (EAAT antagonist, $1 \mu \mathrm{M}$, Tocris Bioscience) (Shimamoto et al., 2004); and TTX (NaV channel antagonist, $1 \mu \mathrm{M}$, Sigma). Drugs were kept as $1000 \times$ stock in $\mathrm{H}_{2} \mathrm{O}$ (APV, CPA, CPP, DHK, D-serine, gabazine, ifenprodil, TTX) or DMSO (DNQX, DPCPX, TFB-TBOA).

\section{Results}

\section{Measuring extracellular glutamate dynamics in the cerebral cortex using glutamate imaging}

We imaged iGSs in the adult mouse cerebral cortex (layer II/III) using the extracellular facing, membrane-tethered glutamate sensor, iGluSnFr (Marvin et al., 2013). C57BL/6 mice were infected with adeno-associated viruses expressing iGluSnFr via intracortical injection. Two to 4 weeks after infection, acute cortical brain slices were prepared, and iGSs were evoked via electrical stimulation in the deep cortical layers. Electrical stimulation activated ascending axons and induced glutamate release in layer II/III. iGSs were recorded in the presence of AMPA and NMDA receptor antagonists (DNQX $20 \mu \mathrm{M}$ and CPP $10 \mu \mathrm{M}$, respectively). Fluorescence responses were imaged using a $60 \times$ objective with epifluorescence LED illumination, and images were collected at a $100 \mathrm{~Hz}$ frame rate. Within the area of cortex imaged, fluorescence responses showed little spatial heterogeneity (likely due to epifluorescence imaging modality and subsequent out of focus fluorescence), and thus all data were quantified from a fluorescence signal spatially averaged over $0.01 \mathrm{~mm}^{2}$ (Fig. 1A). The fluorescence increase and subsequent decay were quantified by the peak iGS amplitude $(\Delta \mathrm{F} / \mathrm{F})$ and decay time (exponential decay function) (Fig. $1 B-D$ ). In response to a single stimulus, iGSs rose robustly within sequential imaging frames (interframe interval $=10 \mathrm{~ms})$ and rapidly returned to baseline $(20.8 \pm 0.6 \mathrm{~ms}$ decay time, GFAP-iGluSnFr) (Diamond, 2005; Armbruster et al., 2014; Hanson et al., 2015). For comparison of stimulation intensities to established assays, stimulus-evoked AMPA currents recorded from layer II/III pyramidal neurons had a peak amplitude of $90 \pm 28 \mathrm{pA}$ (SEM, $N=8$ cells).

To validate that iGS decays represent the kinetic of glutamate clearance, we tested the effects of EAAT inhibitors. Inhibition of all sodium-dependent glutamate transport (TFB-TBOA, $1 \mu \mathrm{M}$ ) (Shimamoto et al., 2004) or selective inhibition of GLT-1 (DHK, $300 \mu \mathrm{M}$ ) (Arriza et al., 1994) significantly increased iGS decay times (Fig. $1 B-D$ ). TFB-TBOA had a larger effect on iGS decays, whereas DHK had a smaller but significant effect. Similar to previous reports (Marvin et al., 2013), blockade of EAATs increased the iGS peak. As with iGS decay time, blockade of all EAATs had a significantly larger effect on iGS peak compared with blockade of GLT-1 alone (Fig. 1D). These findings are consistent with previous studies of EAAT function as measured both biochemically and electrophysiologically and show that iGluSnFr imaging can be used to measure glutamate clearance in the adult cortex as has been reported in the striatum (Parsons et al., 2016). 
A

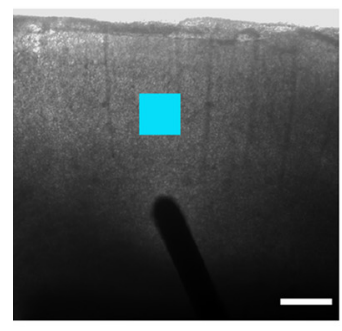

B

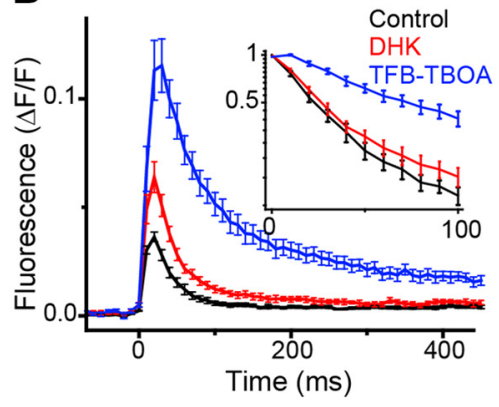

C

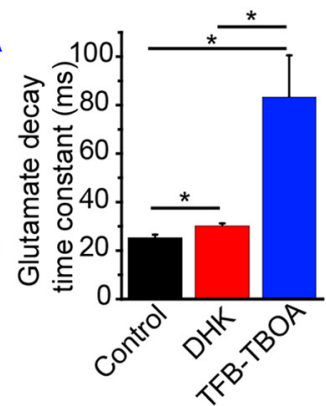

D

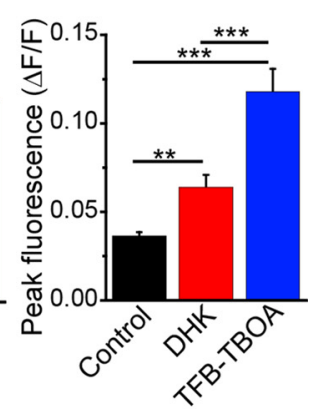

Figure 1. iGluSnFr assay of stimulus evoked glutamate transients. $A$, Representative $4 \times$ bright-field image showing placement of stimulus electrode in the deep cortical layers and imaged area in layer II/III of the cortex (blue square). Scale bar, $250 \mu \mathrm{m}$. B, Average fluorescence response using hSyn-iGluSnFr imaging to a single electrical stimulus. Inset, Semilog plot of poststimulus decay. C, Poststimulus glutamate decay was slowed by DHK and TFB-TBOA for a single stimulus; $N=7$ slices. D, Peak fluorescence was significantly increased with DHK and TFB-TBOA; $N=8$ slices. Statistical tests: paired $t$ tests. ${ }^{*} \alpha=0.05$ (Holm-Bonferroni multiple-comparison correction). ${ }^{* *} \alpha=0.01$ (Holm-Bonferroni multiple-comparison correction). ${ }^{* * *} \alpha=0.001$ (Holm-Bonferroni multiple-comparison correction).

A

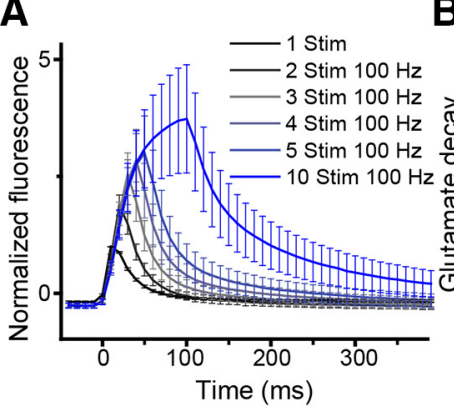

E

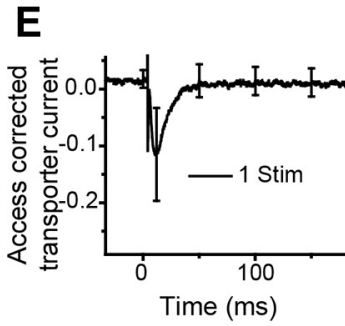

B

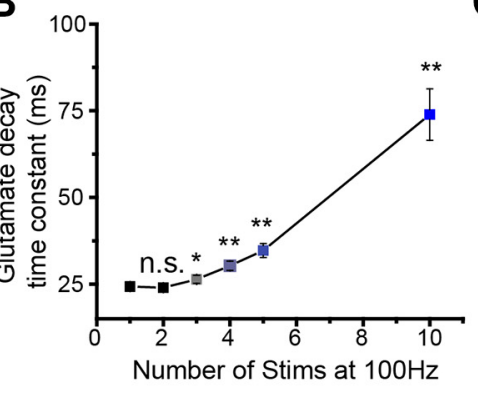

C

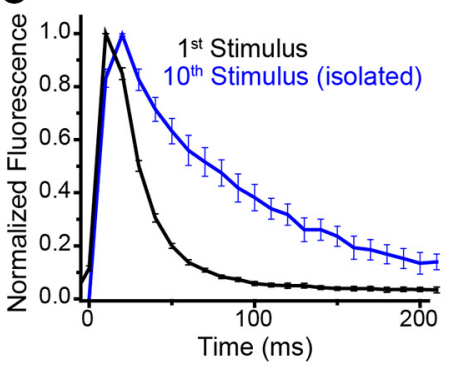

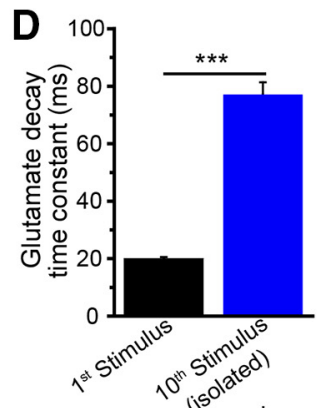
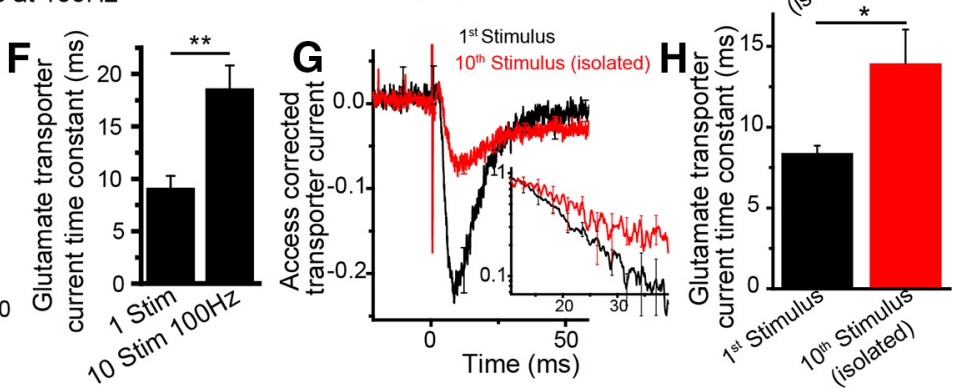

Figure 2. Stimulus-dependent slowing of glutamate clearance. $\boldsymbol{A}$, Average traces of GFAP-iGluSnFr with responses to 1,2,3,4,5, and 10 stimuli at $100 \mathrm{~Hz}$, normalized to 1 stim response, show a stimulus-dependent slowing of glutamate clearance. $B$, Exponential decay time constants of glutamate clearance; $N=7$ slices. $C$, The 10 th stimulus in a $100 \mathrm{~Hz}$ train is isolated by subtracting the previous 9 stimuli and compared with a single stimulus. $\boldsymbol{D}$, The isolated 10 th stimulus shows significant slowing compared with a single stimulus; $N=17$ slices. $E$, Average glutamate transporter currents recorded from whole-cell patch-clamped astrocytes show similar stimulus-dependent slowing of glutamate clearance for 1 and 10 stimuli at $100 \mathrm{~Hz}$. F, Exponential decay time constants of glutamate transporter currents; $N=6$ cells. $\boldsymbol{G}$, The 10th stimulus in a $100 \mathrm{~Hz}$ train of GTCs isolated by subtracting the previous 9 stimuli and compared with a single stimulus. $\boldsymbol{H}$, The isolated 10 th stimulus is significantly slowed compared with a single stimulus; $N=7$ cells. Statistical tests: paired $t$ tests. ${ }^{*} \alpha=0.05$ (Holm-Bonferroni multiple-comparison correction). ${ }^{* *} \alpha=0.01$ (Holm-Bonferroni multiple-comparison correction). ${ }^{* * *} \alpha=0.001$ (Holm-Bonferroni multiple-comparison correction).

\section{Presynaptic activity slows glutamate clearance in a stimulus number-dependent manner}

Because neuronal activity evokes changes in ionic gradients and astrocyte membrane potential (Orkand et al., 1966; Meeks and Mennerick, 2007), both of which modulate EAAT function (Levy et al., 1998), we hypothesized that high-frequency presynaptic activity may affect glutamate clearance. To test this hypothesis, we examined iGSs evoked by trains of $100 \mathrm{~Hz}$ stimulation of ascending axons. iGSs grew in amplitude in response to an increasing number of stimuli, consistent with repetitive synaptic activation. iGS decay time slowed progressively when more than two $100 \mathrm{~Hz}$ stimuli were delivered (Fig. 2A,B). After 3 stimuli, iGS decays were slightly, but significantly, slowed $(8.5 \%$ increase). When 10 stimulations were delivered at $100 \mathrm{~Hz}$, iGS decay times were slowed to $73.9 \pm 7.4 \mathrm{~ms}$ from $24.3 \pm 0.6 \mathrm{~ms}$ for 1 stimulus. This represents a threefold slowing of glutamate recovery compared with a single stimulation. To isolate the response response to the 10th stimulus, we used a subtractive approach. Nine and 10 stimuli trains were interleaved, and the response to 9 stimulations was subtracted from the response to 10 stimulations to isolate the response of only the 10th stimulus. The isolated response, the 10th stimulus was significantly slowed (Fig. $2 C, D)$ compared with a single stimulus. This indicates that the stimulus-dependent slowing of iGSs we report is not an artifact of glutamate accumulation during train stimulation but rather reflects slowed transport.

To confirm the iGluSnFr-based findings, we recorded GTCs via whole-cell patch-clamp recording from individual astrocytes. GTCs are generated by the electrogenic activity of EAATs, which carry positive charge into the astrocyte with each molecule of 

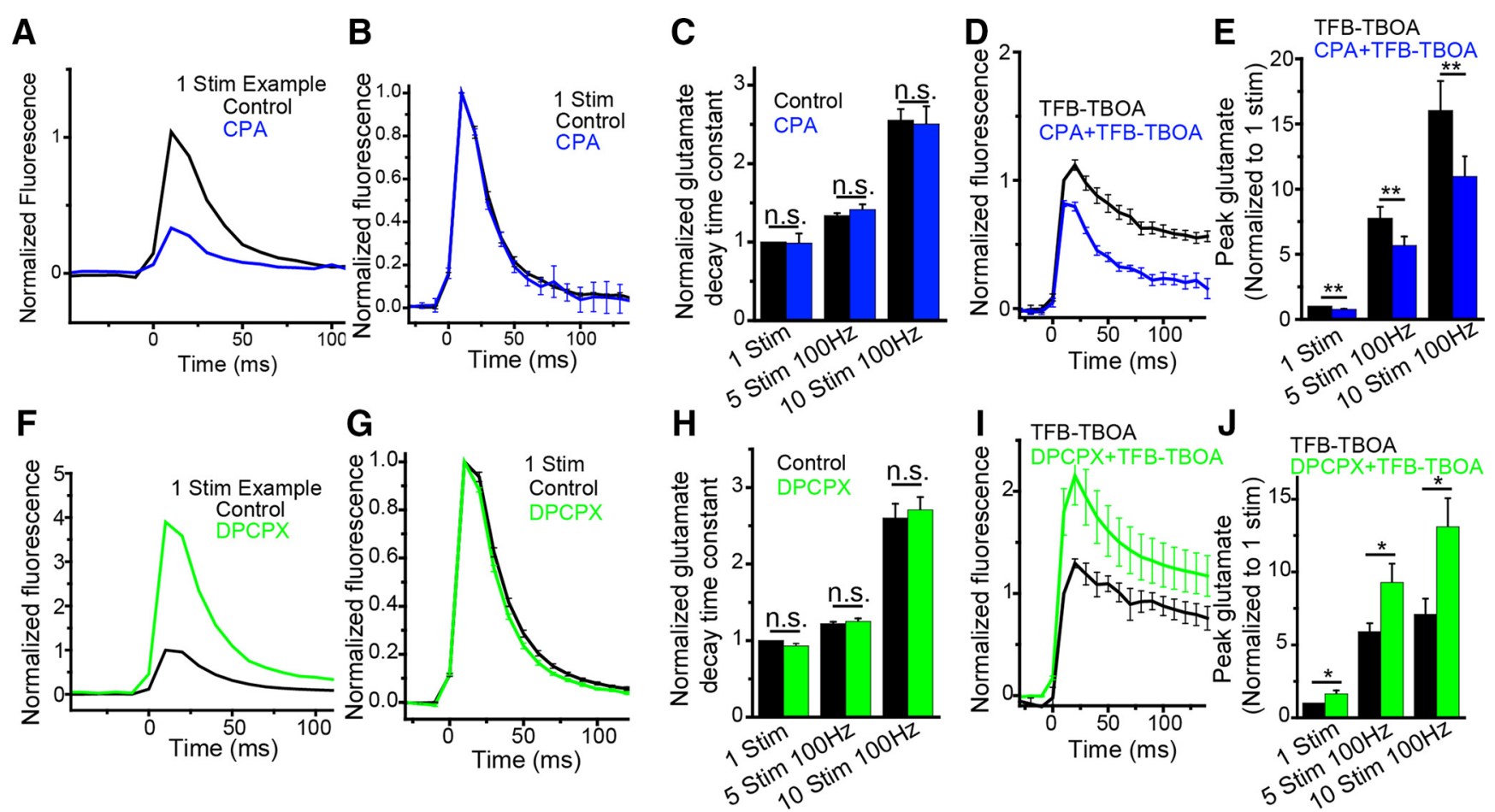

Figure 3. Slowing of glutamate clearance is independent of the amount of glutamate released. $A$, Single slice example trace of GFAP-iGluSnFR response to a single stimulus for control and the adensosine $A_{1}$-receptor agonist CPA, normalized to 1 stim control. $B$, Average normalized traces to a single stimulus for control or CPA. $C$, Time constants of glutamate clearance are unchanged by the application of CPA for 1,5, or 10 stimuli at $100 \mathrm{~Hz}$. Statistical tests: Wilcoxon signed rank test. $D$, Average GFAP-iGluSnFr response in TFB-TBOA with control or CPA to characterize the amount of glutamate released in response to a single stimulus. $E$, Amount of glutamate released is quantified in TFB-TBOA, normalized to a single stimulus for 1,5 , or 10 stimuli at $100 \mathrm{~Hz}$ with or without CPA showing significant reductions in glutamate release with $C P A ; N=11$ slices. $F$, Single slice example trace of GFAP-iGluSnFR response to a single stimulus for control of the adenosine $A_{1}$-receptor antagonist DPCPX, normalized to control. $\boldsymbol{G}$, Average normalized traces to a single stimulus for control or DPCPX. $\boldsymbol{H}$, Time constants of glutamate clearance are unchanged by the application of DPCPX for 1,5 , and 10 stimuli at $100 \mathrm{~Hz}$. Statistical tests: paired $t$ tests. $N=11, N=10$, and $N=11$ slices, respectively. I, Average GFAP-iGluSnFr response in TFB-TBOA with control or DPCPX to characterize the amount of glutamate released in response to a single stimulus. $J$, Glutamate release is significantly increased with DPCPX for 1, 5 , and 10 stimuli at $100 \mathrm{~Hz}$. Statistical tests: paired $t$ tests. $N=$ $11, N=10$, and $N=11$ slices, respectively. ${ }^{*} \alpha=0.05$ (Holm-Bonferroni multiple-comparison correction). ${ }^{* *} \alpha=0.01$ (Holm-Bonferroni multiple-comparison correction). ${ }^{* * *} \alpha=0.001$ (Holm-Bonferroni multiple-comparison correction).

glutamate translocated, and were evoked by stimulation protocols identical to those used in iGluSnFr experiments. To isolate GTCs, we performed stimulation before and after inhibition of all EAATs (TFB-TBOA), to allow subtraction of any non-transportmediated currents. This single-cell approach to quantify glutamate uptake confirmed our findings using iGluSnFr imaging. Synaptically evoked GTC decay times were significantly slowed following 10 stimuli $(100 \mathrm{~Hz})$ compared with a single stimulation (Fig. 2E,F). Similar to the iGluSnFr, the isolated 10th stimulus showed similar slowing as the train (Fig. $2 G, H$ ). These data, using two distinct assays of glutamate clearance, show that presynaptic activity slows glutamate uptake by cortical astrocytes. Last, for both the iGluSnFr and GTC assays, all responses were abolished by addition of TTX $(1 \mu \mathrm{M})$ (data not shown), showing that the signal is specific to synaptically released glutamate.

For the sake of clarity, the term "glutamate clearance" is often used to describe glutamate uptake by astrocytes. It is important to note, however, that GTCs are an indirect measure of extracellular glutamate dynamics, in addition to being distorted by the electrical filtering properties of the astrocyte. iGSs, on the other hand, directly report extracellular glutamate levels with only minimal distortion due to the binding properties of iGluSnFr. For clarity, we will use the term "glutamate clearance" to refer to the iGS results and conclusions drawn from both assays together, whereas we use "glutamate uptake" to refer to conclusions drawn from GTCs alone.
Activity-dependent slowing of glutamate clearance is independent of the amount of glutamate released

A simple explanation for prolonged iGSs after high-frequency presynaptic activity is that, when more glutamate is released, it takes longer for astrocytes to remove it from the extracellular space. To test this hypothesis, we modulated presynaptic glutamate release, by pharmacologically targeting the adenosine $\mathrm{A}_{1}$-receptor while keeping stimulation parameters constant. Adenosine $A_{1}$-receptor agonists inhibit presynaptic calcium channels, thereby decreasing vesicular release probability $\left(\mathrm{P}_{\mathrm{r}}\right)$ (Dunwiddie and Fredholm, 1984); adenosine $\mathrm{A}_{1}$-receptor antagonists do the opposite. Changing $\mathrm{P}_{\mathrm{r}}$ alters the total number of vesicles released over the course of a stimulus train, and hence the amount of glutamate released. First, we used the adenosine $A_{1}$ receptor agonist CPA $(4 \mu \mathrm{M})$ to decrease stimulus-evoked glutamate release by decreasing $\mathrm{P}_{\mathrm{r}}$. This greatly reduced iGS peak amplitude (as measured in TFB-TBOA to characterize total release) but had no effect on iGS decay time (Fig. 3A-E). Next, we increased glutamate release by increasing $\mathrm{P}_{\mathrm{r}}$ with the adenosine A1-receptor antagonist DPCPX $(0.3 \mu \mathrm{M})$ (Lee and Reddington, 1986). DPCPX significantly increased the peak iGS (as quantified in TFB-TBOA) but again did not affect iGS decay time (Fig. $3 F-J)$.

Last, increasing the stimulus intensity twofold (resulting in the activation of more, distinct ascending axons) increased iGS amplitude but again did not affect iGS decay time (data not 

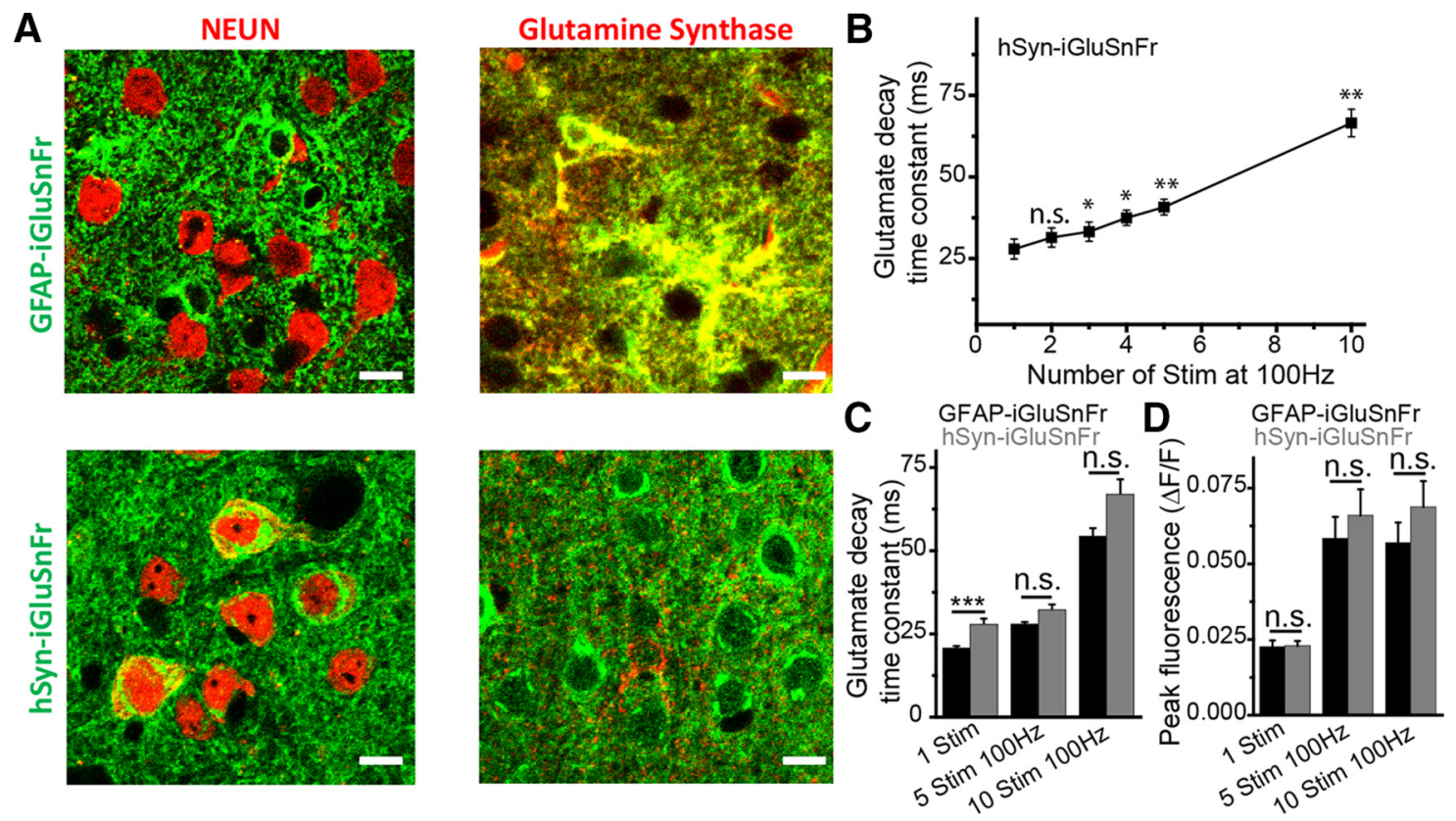

Figure 4. Stimulus-dependent slowing of glutamate uptake affects glutamate signals seen using neuronal expression of iGluSnFr. A, High-magnification immunofluorescent images of cortices infected with either the GFAP-iGluSnFr (top) or the hSyn-iGluSnFr (bottom) coimmunolabeled with anti-GFP and either a neuronal (NEUN, left) or astrocytic (glutamine synthase, right) marker. Scale bar, $10 \mu \mathrm{m}$. B, Response of hSyn-iGluSnFr to different number of stimuli at $100 \mathrm{~Hz}$, showing similar slowing as GFAP-iGluSnFr (Fig. $2 B)$. $N=6$ slices. Statistical tests: paired $t$ tests. C, Poststimulus glutamate clearance decay time constant is slower in hSyn-iGluSnFr compared with GFAP-iGluSnFr for 1 stimuli, but not for 5 and 10 stimuli at $100 \mathrm{~Hz}$. Statistical tests: Mann-Whitney test. D, Peak fluorescence shows no significant differences between the GFAP and hSyn-iGluSnFr reporters. Statistical tests: Mann-Whitney test. $N=23$ and $N=18$ slices for GFAP and hSyn-iGluSnFr, respectively; 15 slices for 5 stim hSyn-iGluSnFr. ${ }^{*} \alpha=0.05$ (Holm-Bonferroni multiple-comparison correction). ${ }^{* *} \alpha=0.01$ (Holm-Bonferroni multiple-comparison correction). ${ }^{* * *} \alpha=0.001$ (Holm-Bonferroni multiple-comparison correction).

shown). Together, these results show that stimulus-dependent slowing of glutamate clearance is not driven by the amount of glutamate released, similar to previous reports (Diamond, 2005; Armbruster et al., 2014; Hanson et al., 2015) and refutes the hypothesis that iGS slowing occurs due to increased extracellular glutamate load.

\section{Activity-dependent slowing of glutamate uptake affects} glutamate dynamics at neuronal surfaces

iGluSnFr can be selectively expressed in either neurons or astrocytes by using different promoter constructs in the adenoassociated viruses (neuronal expression: hSynapsin promoter; astrocytic expression: GFAP promoter). To determine whether the activity-dependent slowing of glutamate clearance affects glutamate dynamics at neuronal surfaces, we expressed iGluSnFr in neurons and examined evoked iGSs. Cell-type specific expression was confirmed by colocalization of GFP immunoreactivity with either glutamine synthase (astrocytic marker) or NEUN (neuronal marker) (Fig. 4A). iGluSnFr expression was highly selective, enabling us to examine extracellular glutamate dynamics preferentially at either the neuronal or astrocytic surface. Glutamate clearance, as measured using neuronal hSyn-iGluSnFr, was slowed by presynaptic activity (Fig. $4 B$ ), similar to our studies using GFAP-iGluSnFr (Fig. 2B). This confirms that alterations in glutamate dynamics seen at astrocytes surfaces also affect the glutamate environment at the neuronal surface. As a side note, when GFAP-iGluSnFr and hSyn-iGluSnFr iGSs were compared, iGS decays were slightly, but significantly, faster at astrocytic, compared with neuronal membranes for single stimulus (Fig. $4 C$ ), although iGS peaks were identical (Fig. 4D). This likely reflects the abundant expression of EAATs on the astrocyte surface and suggests some spatial heterogeneity in extracellular glutamate dynamics. It should be noted that the hSyn-iGluSnFr is expressed throughout the neuronal membrane, and its distribution is likely unique to that of glutamate receptors. As a result, hSyn-iGluSnFr responses should not be taken as a proxy for glutamate receptor activation.

\section{Frequency-dependent modulation of glutamate clearance}

Next, we asked whether the stimulation-dependent slowing of glutamate clearance varied with stimulus frequency. Using the GFAP-iGluSnFr reporter, we examined iGSs evoked by trains of 5 or 10 stimuli at $10 \mathrm{~Hz}$ (Fig. $5 \mathrm{~A}$ ), $30 \mathrm{~Hz}$ (Fig. $5 B$ ), $60 \mathrm{~Hz}$ (Fig. 5C), and $100 \mathrm{~Hz}$ (Fig. 5D). iGS decay times were slowed compared with single stimulus for 30,60 , and 100 , but not $10 \mathrm{~Hz}$ stimulus trains (Fig. 5E). iGS decay times slowed similarly for all stimulation frequencies $\geq 30 \mathrm{~Hz}$. Increasing the number of stimuli, however, increased the magnitude of slowing (Fig. $5 E$ ). Increasing the stimulus frequency changed the total amount of glutamate released (Fig. 5F) and amount of glutamate present at the end of stimulation (data not shown); however, neither correlated with iGS decay. This demonstrates that the stimulus number, rather than the amount of glutamate, contributes to the slowed glutamate clearance. hSyn-iGluSnFr showed similar responses for all measures (data not shown). These data show that there is a steep transition in the frequency dependence of activity-induced slowing of glutamate clearance and that the magnitude of slowing is driven by the number of stimuli delivered.

\section{Recovery of glutamate uptake occurs rapidly}

To determine how long activity-dependent glutamate clearance slowing persists following a stimulus train, we increased the interval between the ninth and 10th stimulus in our $100 \mathrm{~Hz}$ stimulation protocol. The first 9 stimuli were delivered at $100 \mathrm{~Hz}$, and the interval between the ninth and 10th stimulus was set to $10 \mathrm{~ms}$ (identical to $100 \mathrm{~Hz}$ ), $50 \mathrm{~ms}$, or $100 \mathrm{~ms}$ (Fig. 6A). We then isolated 
the iGS response to the 10th stimulus by subtracting the traces of the first 9 stimuli. The iGS decay time of the 10th stimulus was significantly faster at $50 \mathrm{~ms}$ compared with $10 \mathrm{~ms}$, and no further change was observed at $100 \mathrm{~ms}$ (Fig. 6B), indicating the rapid recovery of glutamate clearance following stimulus trains $(<50 \mathrm{~ms})$.

\section{Activity-dependent slowing of} glutamate clearance is input specific The activity-dependent modulation of glutamate uptake we report may occur with input specificity or may occur more broadly. To disambiguate these possibilities, we stimulated two different axonal pathways (ascending cortical connections and lateral intracortical connections), which both evoke glutamate release, while imaging cortical layer II/III with the iGluSnFr sensor (Fig. 7A). Both ascending and intracortical stimulation showed robust stimulus-dependent glutamate release, similar iGS decay times (Fig. $7 B, C$ ), and comparable stimulation thresholds (see Materials and Methods). Importantly, both pathways showed stimulusdependent slowing of glutamate clearance (Fig. $7 B, C$ ). Of note, the magnitude of glutamate uptake slowing was slightly, but significantly, greater for the intracortical pathway.

Using this dual stimulation paradigm, we tested whether stimulating one input affected the glutamate clearance time of the other, independent input. We alternated between stimulus protocols consisting of (1) 9 stimuli of the ascending pathway, (2) stimulus trains containing 10 stimuli on the ascending pathway, and (3) 9 stimuli on the ascending pathway followed by a 10th stimulus on the intracortical stimulator. Using this stimulation approach, we isolated the response to the 10th stimulus by subtracting the response to the first 9 stimuli, similar to the previous experiments (Figs. 6, 7D). When the 10th stimulus was delivered via the ascending stimulator (which had received 9 previous stimuli), iGSs decays were significantly slowed compared with the 10th stimulus delivered to the unstimulated, intracortical pathway (Fig. 7D,E). This shows that, within the same imaging field, iGS decay times were normal when a previously unstimulated input was activated, even when other nearby inputs were activated $10 \mathrm{~ms}$ prior. This demonstrates that the activity-dependent slowing of iGSs occurs in an input-specific manner.

Next, we repeated this experiment using GTCs, which measure evoked currents from the domain of a single astrocyte. Us-
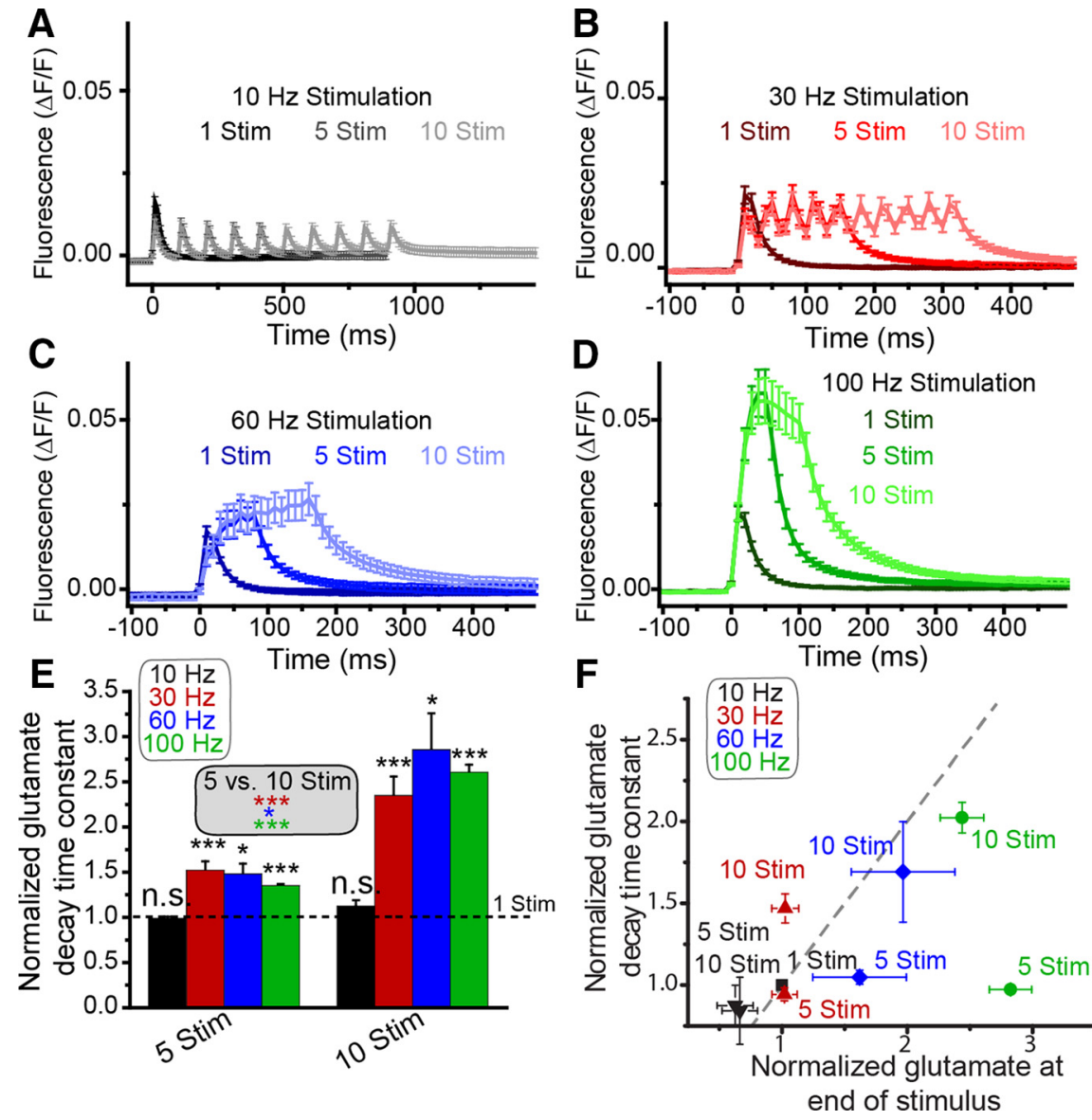

Figure 5. Stimulus number and frequency dependence of glutamate clearance. Average GFAP-iGluSnFr traces for 5 and 10 stimuli are compared with a single stimulus for $10 \mathrm{~Hz}(\boldsymbol{A}), 30 \mathrm{~Hz}(\boldsymbol{B}), 60 \mathrm{~Hz}(\boldsymbol{C})$, and $100 \mathrm{~Hz}(\boldsymbol{D})$ stimulation. For glutamate accumulation during the stimulus train, see also Figure $S 7 A$ (available at www.jneurosci.org as supplemental material). $\boldsymbol{E}$, The 10 $\mathrm{Hz}$ shows no change in the poststimulus glutamate clearance time constant; meanwhile, 30,60, and $100 \mathrm{~Hz}$ stimulation shows slowing of poststimulus glutamate time constant compared with both a single stimulus and with increasing stimulus number. Statistical tests: paired $t$ tests. ${ }^{*} \alpha=0.05$ (Holm-Bonferroni multiple-comparison correction). ${ }^{* *} \alpha=0.001$ (Holm-Bonferroni multiple-comparison correction). $N=9, N=18, N=9$, and $N=23$ slices for $10,30,60$, and $100 \mathrm{~Hz}$, respectively. $\boldsymbol{F}$, Scatterplot of the amount of glutamate at the end of stimulus plotted against the poststimulus glutamate decay time constant. There was no correlation of extracellular glutamate and decay time constant. Dashed gray line indicates identity line.

A
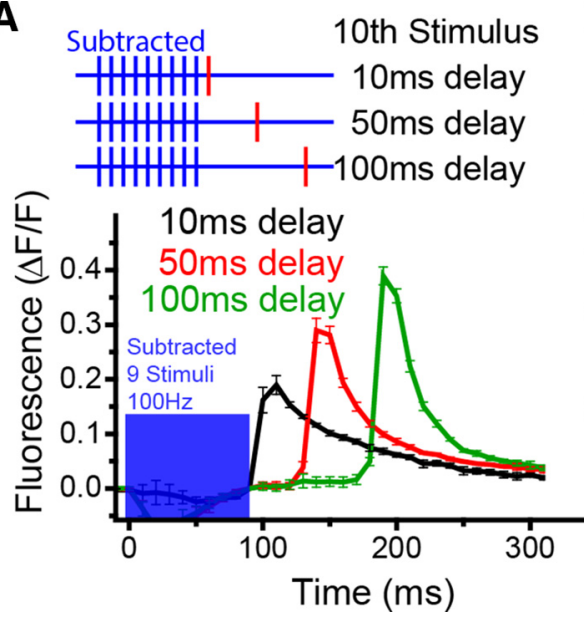

Figure 6. Recovery of glutamate clearance is rapid after cessation of high-frequency activity. $A$, The 10th stimulus of a train is isolated by subtracting recordings of the previous 9 stimuli. The 10th stimulus is delayed by 10,50 , or 100 ms following the ninth stimulus. Average GFAP-iGluSnFr trace of the isolated 10th stimulus. $\boldsymbol{B}$, Time constant of glutamate clearance for the isolated 10th stimulus shown, normalized to the decay time constant in response to a single stimulus. The 10th stimulus is significantly slowed with a 10 ms delay, compared with a 50 or 100 ms delay; $N=18$ slices. Statistical tests: paired $t$ tests. ${ }^{* * *} \alpha=0.001$ (HolmBonferroni multiple-comparison correction). 
A
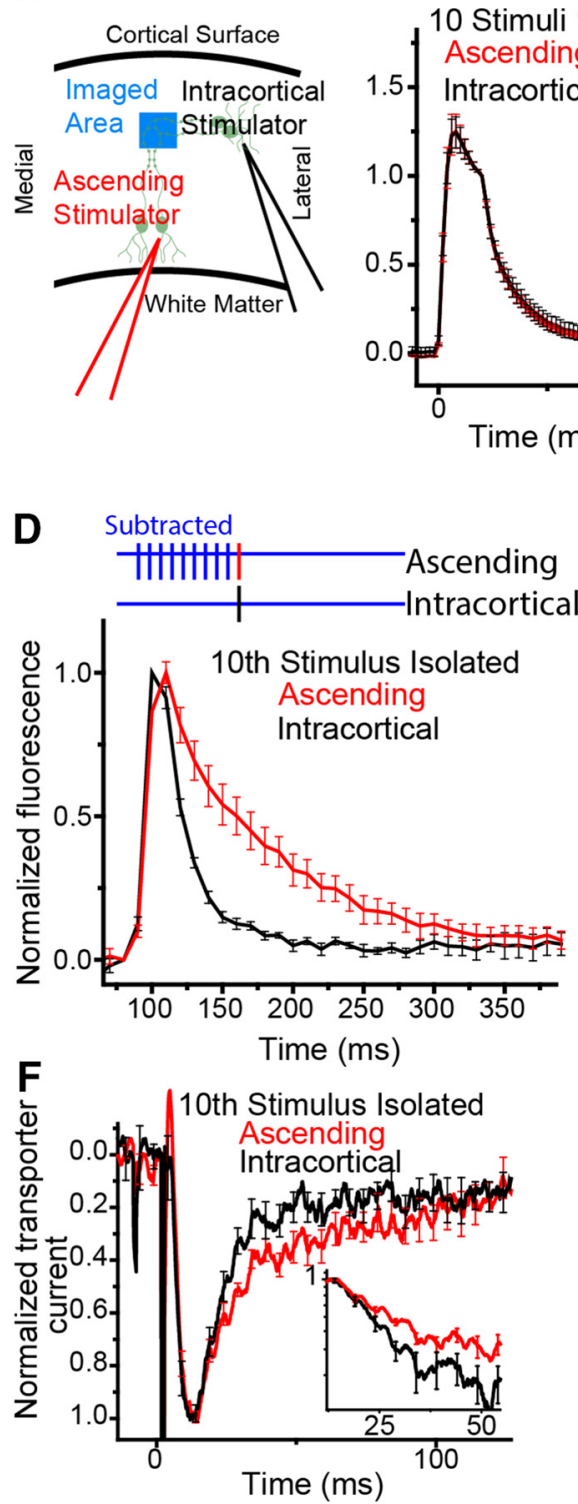
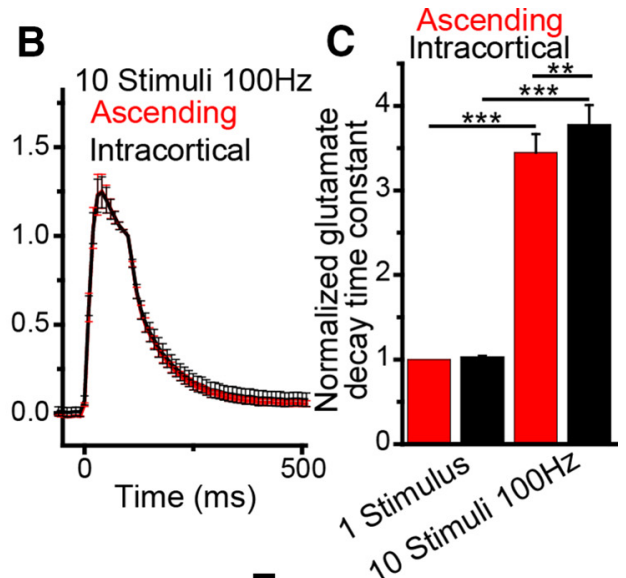

$E$
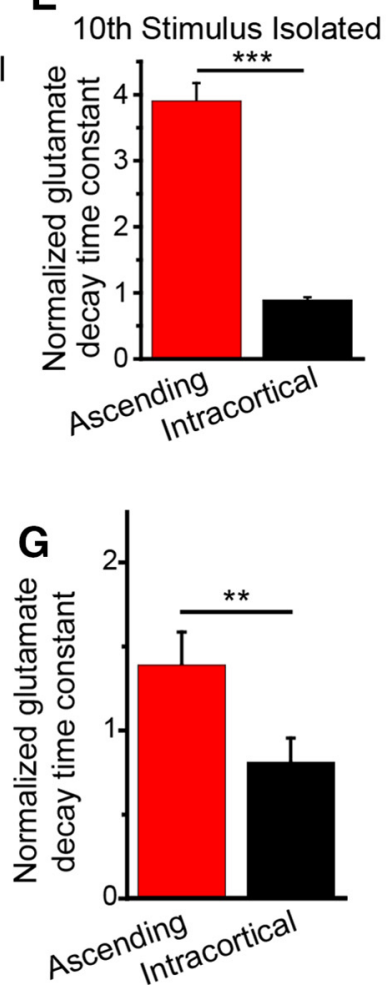

Figure 7. Glutamate clearance slowing is locally modulated. $\boldsymbol{A}$, Layout of two stimulators activating ascending or intracortical inputs into layer II/III of the cortex. B, Average normalized GFAP-iGluSnFr response to ascending or intracortical stimulation with 10 stimuli at $100 \mathrm{~Hz} ; \mathrm{N}=17$ slices. $\mathrm{C}$, Glutamate clearance slows similarly for the ascending and intracortical inputs, normalized to 1 stimulus on the ascending stimulator; $N=17$ slices. Statistical tests: paired $t$ tests. Significance determined with Holm-Bonferroni multiple-comparison correction. $\boldsymbol{D}$, Nine stimuli at $100 \mathrm{~Hz}$ are given to the ascending inputs followed either by a 10 th stimulus to the ascending stimulator or the intracortical stimulator. The 10th stimulus is isolated by subtracting recordings of the 9 stimuli train. Average GFAP-iGluSnFr response of the ascending and intracortical 10th stimulus; $N=7$ slices. $\boldsymbol{E}$, Glutamate clearance time constant normalized to 1 stimulus on the ascending stimulator shows significant differences in decay of the 10th stimulus for the ascending and intracortical inputs. Statistical tests: paired $t$ tests. $N=17$ slices. $F$, Astrocyte GTC recording with the same stimulus paradigm as in $\boldsymbol{D}$; traces are TFB-TBOA subtracted. Average GTC traces shown; $N=11$ cells. $\mathbf{G}$, GTC decay times normalized to a single stimulus (ascending input) show significant difference between the ascending and intracortical 10th stimulus decays; $N=$ 11 cells (Wilcoxon signed rank test). ${ }^{* *} \alpha=0.01 ;{ }^{* * *} \alpha=0.001$.

ing GTCs, the 10th stimulus was isolated similarly to the imaging experiments. GTCs were significantly slowed on the 10th stimulus delivered on the ascending stimulator (which had received 9 previous stimuli) compared with the 10th stimulus delivered to the unstimulated, intracortical pathway (Fig. $7 F, G$ ). In this assay, the magnitude of slowing measured using GTCs was not as great when measured with iGluSnFr imaging, consistent with our previous findings (Fig. 2). This demonstrates that, within the do- main of an individual astrocyte, stimulusdependent slowing of glutamate uptake occurs with input specificity.

NR2A-mediated NDMAR current decay kinetics mirror activity-dependent changes in glutamate uptake

To examine the synaptic consequences of slowed glutamate clearance, we asked whether the decay time of NR2A-mediated NMDAR currents reflected the prolonged glutamate persistence in the extracellular space. As NMDAR EPSCs can be slowed by activating NMDARs with different kinetics (NR2B, slow kinetics; NR2A, faster kinetics) (Arnth-Jensen et al., 2002; Lozovaya et al., 2004), we used the NR2Bspecific antagonist ifenprodil (Williams, 1993) (5 $\mu \mathrm{M})$ to isolate NR2A-specific EPSCs. Layer II/III pyramidal neurons were patch-clamped and held at $+40 \mathrm{mV}$ to relieve the $\mathrm{Mg}^{2+}$ block of the NMDARs. Single stimulus or trains at 100 $\mathrm{Hz}$ (5 or 10 stimuli) were delivered as in previous experiments. We found that NR2A-mediated NMDAR EPSCs were significantly and progressively slowed by the increased stimuli number (Fig. $8 A, B$ ). The slowing was highly correlated with the slowing of glutamate clearance as assayed using the iGluSnFr assay for these three stimulus conditions (Fig. 8B). Additionally, single stimulus or trains of 5 stimuli at 10,30 , or $100 \mathrm{~Hz}$ were delivered as in previous experiments to test the frequency dependence of the slowing (Fig. 8C). The frequency dependence of NMDAR current slowing mirrored the frequency dependence of activity-dependent slowing of glutamate uptake (Fig. $8 D-F$ ). Five stimuli at $10 \mathrm{~Hz}$ did not significantly slow NMDA EPSC decay times compared with a single stimulus, similar to the $10 \mathrm{~Hz}$ iGluSnFr imaging result (Fig. 5). In contrast, 5 stimuli at $30 \mathrm{~Hz}$ and at $100 \mathrm{~Hz}$ significantly prolonged NMDA EPSCs compared with a single stimulus, again mirroring the iGluSnFr imaging result (Fig. 5). To confirm that the evoked currents were NMDAR-mediated, the NMDA antagonist, APV $(50 \mu \mathrm{M})$, was added and completely blocked the stimulus-evoked currents. These results suggest that the slowed glutamate clearance modulates postsynaptic glutamate receptor activation.

\section{Discussion}

We report a novel form of neuron-astrocyte communication in the adult cerebral cortex in which presynaptic neuronal activity rapidly and reversibly slows glutamate clearance. We have identified this modulatory mechanism using two independent and complimentary techniques to quantify glutamate clearance: iGluSnFr imaging and GTC recording. We have demonstrated a 
A
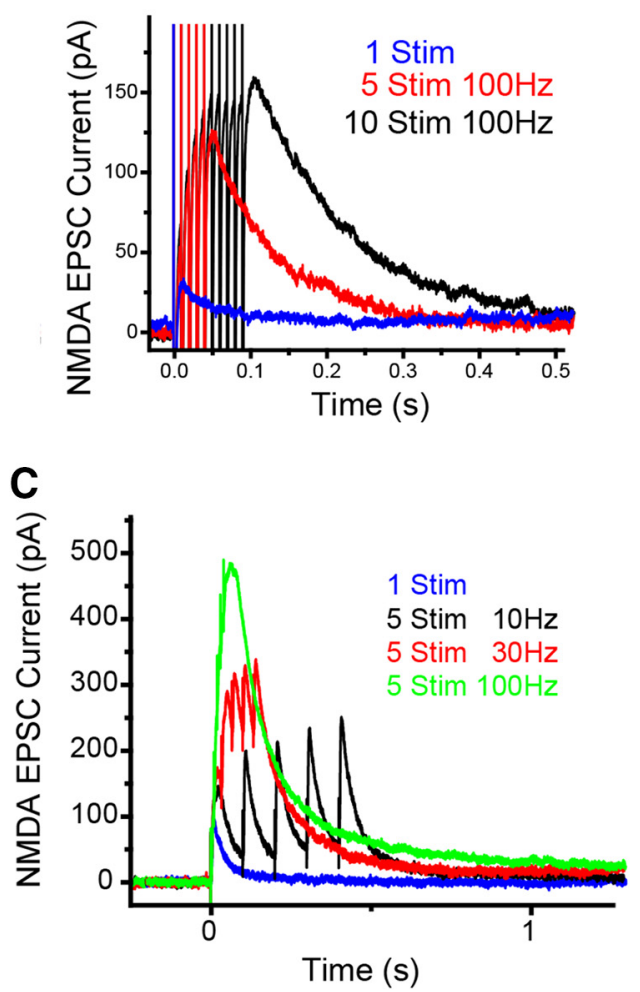

E

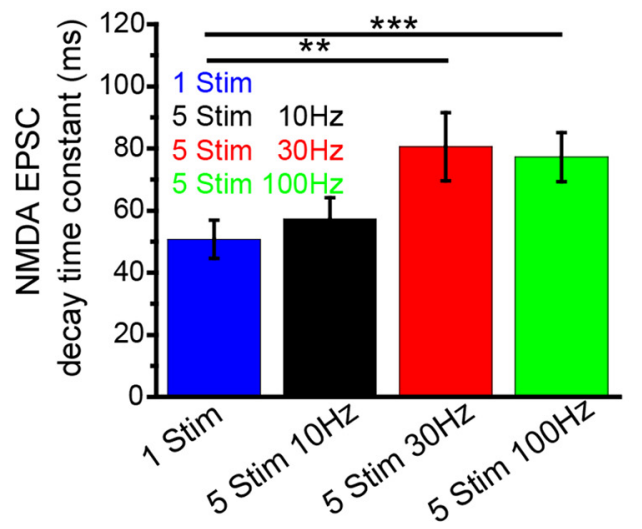

B

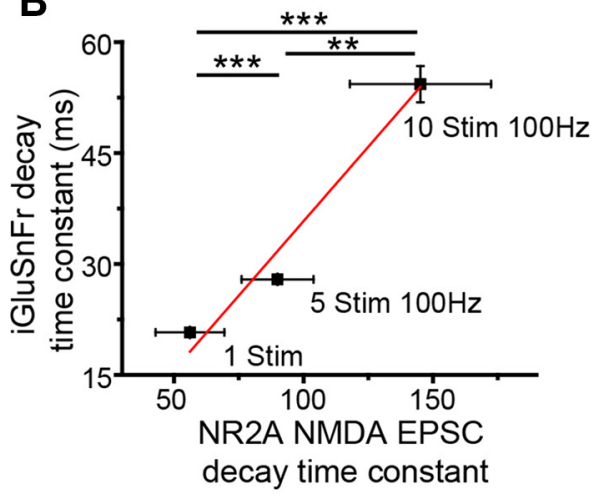

D

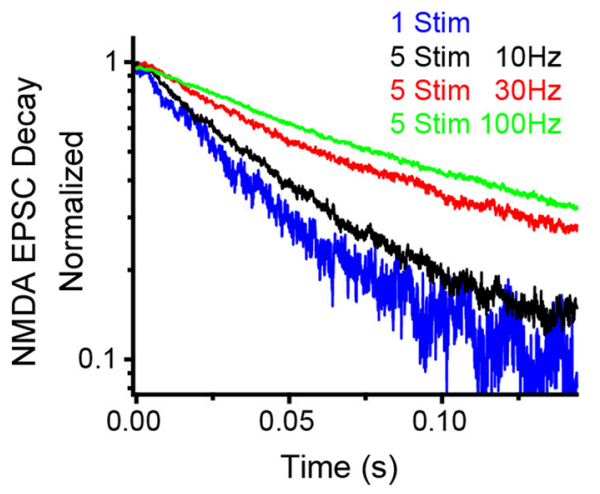

$\mathbf{F}$

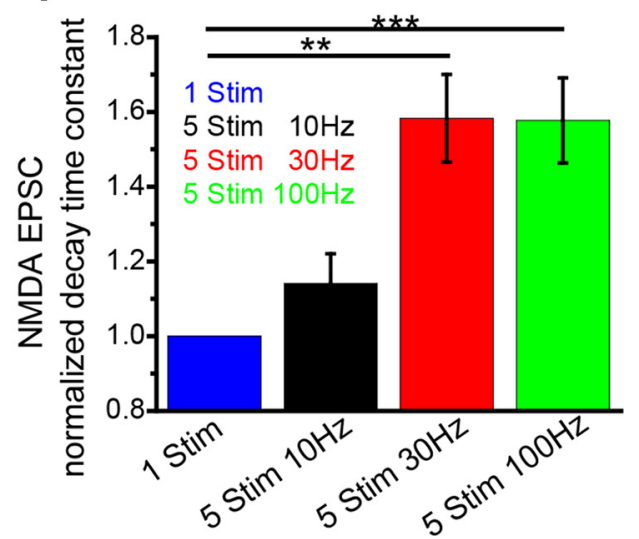

Figure 8. NR2A-NMDA EPSC decays are slowed by presynaptic stimulation with similar stimulus and frequency dependence to glutamate uptake slowing. $A$, Representative traces of NR2Aspecific NMDA receptor EPSCs in response to 1, 5, or 10 stimuli at $100 \mathrm{~Hz}$. $B$, NR2A NMDA EPSC decays show significant slowing with increased stimuli number; $N=5$ cells. The slowing correlates (linear regression in red $R^{2}=0.96$ ) with the slowing of glutamate clearance as assayed by GFAP-iGluSnFr (data from Fig. 5). Statistical tests: log-corrected paired $t$ tests. Significance determined with Holm-Bonferroni multiple-comparison correction. C, Representative traces of NR2A-specific NMDA receptor EPSCs in response to 1 or 5 stimuli at 10, 30, or 100 Hz. D, NR2A-specific NMDA EPSC decays are plotted on a semilog plot, highlighting the frequency dependence of the decays. E, NR2A NMDA EPSC decays show significant slowing at 5 stimuli $30 \mathrm{~Hz}$ and $100 \mathrm{~Hz}$ compared with 1 stimuli, but not at $10 \mathrm{~Hz}$. F, NR2A NMDA EPSC decays normalized to the decay in response to a single stimulus, highlighting the stimulus-dependent slowing of the decays. Statistical tests: paired $t$ tests. ${ }^{*} \alpha=0.05$ (Holm-Bonferroni multiple-comparison correction). ${ }^{* *} \alpha=0.01$ (Holm-Bonferroni multiple-comparison correction). ${ }^{* * *} \alpha=0.001$ (Holm-Bonferroni multiple-comparison correction). $N=10$ cells.

number of properties of this modulatory mechanism: (1) it is independent of the amount of glutamate released; (2) glutamate clearance is only slowed when bursts of activity occur at $\geq 30 \mathrm{~Hz}$; (3) the onset of modulation is rapid $\leq 20 \mathrm{~ms}$; (4) the modulation is specific to the activated inputs; and (5) the restoration of normal clearance is $<50 \mathrm{~ms}$. Last, we have shown that NR2ANMDAR current decay times reflect the activity-dependent changes in glutamate clearance. Interestingly, in a study examining the developing hippocampus, activity-dependent slowing of glutamate clearance was not seen (Diamond and Jahr, 2000). This suggests that there may be regionally or developmentally specific synaptic or astrocytic properties that contribute to activitydependent slowing of uptake.

We report up to threefold slowing in glutamate uptake following bursts of high-frequency activity. Genetic and pharmacological manipulations of transporter expression (Rothstein et al., 2005; Omrani et al., 2009; Goodrich et al., 2013; Higashimori et al., 2013; Petr et al., 2015) and localization (Pannasch et al., 2014; Murphy-Royal et al., 2015) have shown that even small changes in glutamate transport can have significant effects on neuronal 
function. For example, genetic ablation of the neuronal glutamate transporter EAAC1, which constitutes a small fraction of the total glutamate clearance capacity, alters glutamatergic signaling and synaptic plasticity (Scimemi et al., 2009; Holmseth et al., 2012). Altering the diffusional mobility of GLT-1 (MurphyRoyal et al., 2015) or the localization via connexin 30 knock out (Pannasch et al., 2014) similarly alters glutamatergic signaling. Previously, the abundant expression of EAATs has resulted in the view that glutamate transport is a housekeeping function, and disruptions in EAAT function are pathological. Our results, along with recent studies, challenge this view and suggest that glutamate clearance is an active modulatory mechanism controlling extracellular glutamatergic dynamics.

Activity-dependent slowing of uptake prolongs the time in which glutamate remains free in the extracellular space and, thus, may prolong receptor activation, especially for extrasynaptic receptors. Accordingly, our experiments show that NR2ANMDAR EPSCs are slowed in both a stimulus number and stimulus frequency-dependent manner, similar to the slowing of glutamate clearance. Consistent with this, previous studies have shown that neuronal NMDA receptor EPSC decay kinetics are slowed with trains of stimuli (Arnth-Jensen et al., 2002; Grebenyuk et al., 2004; Lozovaya et al., 2004). While some of the slowing occurs due to the activation of distinct NMDA receptor subtypes with diverse decay times, this does not account for the entire slowing (Lozovaya et al., 2004). Our experiments, done in the presence of NR2B-blocker ifenprodil, eliminate the possibility that stimulus-dependent slowing of NMDAR currents results from activation of NMDARs with different kinetics. The similarity in the slowing of glutamate uptake and NR2A-NMDAR current kinetics, while correlative, strongly support our central conclusion that bursts of presynaptic activity slow astrocytic glutamate uptake.

While the mechanism underlying the presynaptic modulation of glutamate clearance remains unclear, we favor a hypothesis that neuronal activity induces local depolarization of astrocyte microdomains, thereby reducing EAAT activity. EAAT function is voltage-dependent (Levy et al., 1998), neuronal activity is known to depolarize astrocytes (Orkand et al., 1966; Meeks and Mennerick, 2007), and growing evidence supports local compartmentalization of changes in astrocyte membrane potential (Ma et al., 2014, 2016). This hypothesis satisfies the properties of the glutamate clearance modulation that we have identified: rapid onset, local modulation, and fast decay. There are, however, some incongruencies with this hypothesis. First, in mouse cortical preparations, neuronal activity does not induce large changes in astrocyte $\mathrm{V}_{\mathrm{m}}$ as measured at the astrocyte soma. Recent studies, however, show that significant astrocytic depolarizations can remain restricted to microdomains due to astrocyte membrane properties (Ma et al., 2014, 2016). This may mask local changes in astrocyte $\mathrm{V}_{\mathrm{m}}$ when monitored only at the soma. Last, a recent study has highlighted that astrocyte $\mathrm{K}^{+}$currents are especially sensitive to NMDA $\mathrm{K}^{+}$efflux compared with AMPA-mediated efflux (Shih et al., 2013). This highlights the specialized relationship between neuronal and astrocytic processes and suggests that NMDA-mediated $\mathrm{K}^{+}$efflux may have distinct effects on astrocyte functions in addition to the presynaptic modulation of glutamate uptake show here. In the future, new tools to assay local ionic and voltage changes at the perisynaptic astrocyte processes may allow us to define the underlying mechanism of the modulation.

One potential mechanism that can be resoundingly eliminated, however, is transport slowing due to increased glutamate challenge. EAATs are abundantly expressed (Lehre and Danbolt, 1998), and multiple studies have demonstrated that glutamate clearance is insensitive to increased glutamate challenge (Diamond, 2005; Wadiche et al., 2006; Armbruster et al., 2014; Hanson et al., 2015). Conceptually, all of these support the hypothesis that the amount of EAAT is not a limiting factor for glutamate transport in the mature brain. Our studies modulating adenosine $A_{1}$ receptors are consistent with this long-standing view of glutamate transport. Additionally, evidence to support this hypothesis comes from the small effect of DHK. The GLT-1-specific inhibitor, DHK, has a minor effect on the glutamate clearance time and no effect on activity-dependent slowing of glutamate clearance (data not shown), despite blocking a large fraction of the available transporters. The small change in clearance could be due to differences in the efficiencies of transport between the transporters EAAC1, GLAST, and GLT-1 (Arriza et al., 1994; Danbolt, 2001). Overall, multiple lines of evidence show that activity-induced slowing of glutamate clearance is independent of the amount of glutamate released.

In conclusion, the activity-dependent slowing of clearance that we report is the first example of an alteration in glutamate clearance kinetics in response to physiologically relevant stimuli. This modulatory mechanism has a large (threefold) dynamic range, occurs following short bursts of activity, and is induced and recovers rapidly. Slowing in glutamate uptake can be detected at neuronal surfaces using hSyn-iGluSnFr, and NR2ANMDAR EPSC decay kinetics mirror changes in uptake. Together, these studies show that high-frequency neuronal activity induces brief, local enhancement of glutamatergic excitation via inhibition of astrocytic glutamate transport.

\section{References}

Afzalov R, Pryazhnikov E, Shih PY, Kondratskaya E, Zobova S, Leino S, Salminen O, Khiroug L, Semyanov A (2013) Low micromolar Ba(2+) potentiates glutamate transporter current in hippocampal astrocytes. Front Cell Neurosci 7:135. CrossRef Medline

Armbruster M, Hampton D, Yang Y, Dulla CG (2014) Laser-scanning astrocyte mapping reveals increased glutamate-responsive domain size and disrupted maturation of glutamate uptake following neonatal cortical freeze-lesion. Front Cell Neurosci 8:277. CrossRef Medline

Arnth-Jensen N, Jabaudon D, Scanziani M (2002) Cooperation between independent hippocampal synapses is controlled by glutamate uptake. Nat Neurosci 5:325-331. CrossRef Medline

Arriza JL, Fairman WA, Wadiche JI, Murdoch GH, Kavanaugh MP, Amara SG (1994) Functional comparisons of three glutamate transporter subtypes cloned from human motor cortex. J Neurosci 14:5559-5569. Medline

Bergles DE, Jahr CE (1997) Synaptic activation of glutamate transporters in hippocampal astrocytes. Neuron 19:1297-1308. CrossRef Medline

Bergles DE, Diamond JS, Jahr CE (1999) Clearance of glutamate inside the synapse and beyond. Curr Opin Neurobiol 9:293-298. CrossRef Medline

Borghuis BG, Marvin JS, Looger LL, Demb JB (2013) Two-photon imaging of nonlinear glutamate release dynamics at bipolar cell synapses in the mouse retina. J Neurosci 33:10972-10985. CrossRef Medline

Chaudhry FS, Lehre KP, van Lookeren Campagne M, Ottersen OP, Danbolt NC, Storm-Mathisen J (1995) Glutamate transporters in glial plasma membranes: highly differentiated localizations revealed by quantitative ultrastructural immunocytochemistry. Neuron 15:711-720. CrossRef Medline

Clements JD, Lester RA, Tong G, Jahr CE, Westbrook GL (1992) The time course of glutamate in the synaptic cleft. Science 258:1498-1501. CrossRef Medline

Danbolt NC (2001) Glutamate uptake. Prog Neurobiol 65:1-105. CrossRef Medline

Davies J, Evans RH, Herrling PL, Jones AW, Olverman HJ, Pook P, Watkins JC (1986) CPP, a new potent and selective NMDA antagonist: depression of central neuron responses, affinity for $\left[{ }^{3} \mathrm{H}\right] \mathrm{D}$-AP 5 binding sites on 
brain membranes and anticonvulsant activity. Brain Res 382:169-173. CrossRef Medline

Diamond JS (2005) Deriving the glutamate clearance time course from transporter currents in CA1 hippocampal astrocytes: transmitter uptake gets faster during development. J Neurosci 25:2906-2916. CrossRef Medline

Diamond JS, Jahr CE (1997) Transporters buffer synaptically released glutamate on a submillisecond time scale. J Neurosci 17:4672-4687. Medline

Diamond JS, Jahr CE (2000) Synaptically released glutamate does not overwhelm transporters on hippocampal astrocytes during high-frequency stimulation. J Neurophysiol 83:2835-2843. Medline

Dunwiddie TV, Fredholm BB (1984) Adenosine receptors mediating inhibitory electrophysiological responses in rat hippocampus are different from receptors mediating cyclic AMP accumulation. Naunyn Schmiedebergs Arch Pharmacol 326:294-301. CrossRef Medline

Edelstein AD, Tsuchida MA, Amodaj N, Pinkard H, Vale RD, Stuurman N (2014) Advanced methods of microscope control using muManager software. J Biol Methods 1:piie10. CrossRef Medline

Evans RH, Francis AA, Jones AW, Smith DA, Watkins JC (1982) The effects of a series of omega-phosphonic alpha-carboxylic amino acids on electrically evoked and excitant amino acid-induced responses in isolated spinal cord preparations. Br J Pharmacol 75:65-75. CrossRef Medline

Goodrich GS, Kabakov AY, Hameed MQ, Dhamne SC, Rosenberg PA, Rotenberg A (2013) Ceftriaxone treatment after traumatic brain injury restores expression of the glutamate transporter, GLT-1, reduces regional gliosis, and reduces post-traumatic seizures in the rat. J Neurotrauma 30:1434-1441. CrossRef Medline

Grebenyuk SE, Lozovaya NA, Tsintsadze TS, Krishtal OA (2004) Postsynaptic $N$-methyl-D-aspartate signalling in hippocampal neurons of rat: spillover increases the impact of each spike in a short burst discharge. Neurosci Lett 361:60-63. CrossRef Medline

Hanson E, Armbruster M, Cantu D, Andresen L, Taylor A, Danbolt NC, Fau-Dulla C, Dulla CG (2015) Astrocytic glutamate uptake is slow and does not limit neuronal NMDA receptor activation in the neonatal neocortex. Glia 63:1784-1796. CrossRef Medline

Heaulme M, Chambon JP, Leyris R, Molimard JC, Wermuth CG, Biziere K (1986) Biochemical characterization of the interaction of three pyridazinylGABA derivatives with the GABAA receptor site. Brain Res 384:224-231. CrossRef Medline

Higashimori H, Morel L, Huth J, Lindemann L, Dulla C, Taylor A, Freeman M, Yang Y (2013) Astroglial FMRP-dependent translational downregulation of mGluR5 underlies glutamate transporter GLT1 dysregulation in the fragile X mouse. Hum Mol Genet 22:2041-2054. CrossRef Medline

Holmseth S, Dehnes Y, Huang YH, Follin-Arbelet VV, Grutle NJ, Mylonakou MN, Plachez C, Zhou Y, Furness DN, Bergles DE, Lehre KP, Danbolt NC (2012) The density of EAAC1 (EAAT3) glutamate transporters expressed by neurons in the mammalian CNS. J Neurosci 32:6000-6013. CrossRef Medline

Honoré T, Davies SN, Drejer J, Fletcher EJ, Jacobsen P, Lodge D, Nielsen FE (1988) Quinoxalinediones: potent competitive non-NMDA glutamate receptor antagonists. Science 241:701-703. CrossRef Medline

Jones TA, Greenough WT (1996) Ultrastructural evidence for increased contact between astrocytes and synapses in rats reared in a complex environment. Neurobiol Learn Mem 65:48-56. CrossRef Medline

Lee KS, Reddington M (1986) 1,3-Dipropyl-8-cyclopentylxanthine (DPCPX) inhibition of $\left[{ }^{3} \mathrm{H}\right] \mathrm{N}$-ethylcarboxamidoadenosine (NECA) binding allows the visualization of putative non-A1 adenosine receptors. Brain Res 368:394398. CrossRef Medline

Lehre KP, Danbolt NC (1998) The number of glutamate transporter subtype molecules at glutamatergic synapses: chemical and stereological quantification in young adult rat brain. J Neurosci 18:8751-8757. Medline

Le Meur K, Galante M, Angulo MC, Audinat E (2007) Tonic activation of NMDA receptors by ambient glutamate of non-synaptic origin in the rat hippocampus. J Physiol 580:373-383. CrossRef Medline

Levy LM, Warr O, Attwell D (1998) Stoichiometry of the glial glutamate transporter GLT-1 expressed inducibly in a Chinese hamster ovary cell line selected for low endogenous $\mathrm{Na}^{+}$-dependent glutamate uptake. J Neurosci 18:9620-9628. Medline
Lozovaya NA, Grebenyuk SE, Tsintsadze TS, Feng B, Monaghan DT, Krishtal OA (2004) Extrasynaptic NR2B and NR2D subunits of NMDA receptors shape 'superslow' afterburst EPSC in rat hippocampus. J Physiol 558:451-463. CrossRef Medline

Ma B, Xu G, Wang W, Enyeart JJ, Zhou M (2014) Dual patch voltage clamp study of low membrane resistance astrocytes in situ. Mol Brain 7:18. CrossRef Medline

Ma B, Buckalew R, Du Y, Kiyoshi CM, Alford CC, Wang W, McTigue DM, Enyeart JJ, Terman D, Zhou M (2016) Gap junction coupling confers isopotentiality on astrocyte syncytium. Glia 64:214-226. CrossRef Medline

MacGregor DG, Chesler M, Rice ME (2001) HEPES prevents edema in rat brain slices. Neurosci Lett 303:141-144. CrossRef Medline

Marvin JS, Borghuis BG, Tian L, Cichon J, Harnett MT, Akerboom J, Gordus A, Renninger SL, Chen TW, Bargmann CI, Orger MB, Schreiter ER, Demb JB, Gan WB, Hires SA, Looger LL (2013) An optimized fluorescent probe for visualizing glutamate neurotransmission. Nat Methods 10:162-170. CrossRef Medline

Meeks JP, Mennerick S (2007) Astrocyte membrane responses and potassium accumulation during neuronal activity. Hippocampus 17:11001108. CrossRef Medline

Minelli A, Barbaresi P, Reimer RJ, Edwards RH, Conti F (2001) The glial glutamate transporter GLT-1 is localized both in the vicinity of and at distance from axon terminals in the rat cerebral cortex. Neuroscience 108:51-59. CrossRef Medline

Murphy-Royal C, Dupuis JP, Varela JA, Panatier A, Pinson B, Baufreton J, Groc L, Oliet SH (2015) Surface diffusion of astrocytic glutamate transporters shapes synaptic transmission. Nat Neurosci 18:219-226. CrossRef Medline

Nimmerjahn A, Kirchhoff F, Kerr JN, Helmchen F (2004) Sulforhodamine 101 as a specific marker of astroglia in the neocortex in vivo. Nat Methods 1:31-37. CrossRef Medline

Ohta K, Araki N, Shibata M, Komatsumoto S, Shimazu K, Fukuuchi Y (1994) Presynaptic ionotropic glutamate receptors modulate in vivo release and metabolism of striatal dopamine, noradrenaline, and 5-hydroxytryptamine: involvement of both NMDA and AMPA/kainate subtypes. Neurosci Res 21:83-89. CrossRef Medline

Omrani A, Melone M, Bellesi M, Safiulina V, Aida T, Tanaka K, Cherubini E, Conti F (2009) Up-regulation of GLT-1 severely impairs LTD at mossy fibre-CA3 synapses. J Physiol 587:4575-4588. CrossRef Medline

Orkand RK, Nicholls JG, Kuffler SW (1966) Effect of nerve impulses on the membrane potential of glial cells in the central nervous system of amphibia. J Neurophysiol 29:788-806. Medline

Pannasch U, Freche D, Dallérac G, Ghézali G, Escartin C, Ezan P, CohenSalmon M, Benchenane K, Abudara V, Dufour A, Lübke JH, Déglon N, Knott G, Holcman D, Rouach N (2014) Connexin 30 sets synaptic strength by controlling astroglial synapse invasion. Nat Neurosci 17:549558. CrossRef Medline

Parsons MP, Vanni MP, Woodard CL, Kang R, Murphy TH, Raymond LA (2016) Real-time imaging of glutamate clearance reveals normal striatal uptake in Huntington disease mouse models. Nat Commun 7:11251. CrossRef Medline

Petr GT, Sun Y, Frederick NM, Zhou Y, Dhamne SC, Hameed MQ, Miranda C, Bedoya EA, Fischer KD, Armsen W, Wang J, Danbolt NC, Rotenberg A, Aoki CJ, Rosenberg PA (2015) Conditional deletion of the glutamate transporter GLT-1 reveals that astrocytic GLT-1 protects against fatal epilepsy while neuronal GLT-1 contributes significantly to glutamate uptake into synaptosomes. J Neurosci 35:51875201. CrossRef Medline

Ransom CB, Sontheimer H (1995) Biophysical and pharmacological characterization of inwardly rectifying $\mathrm{K}^{+}$currents in rat spinal cord astrocytes. J Neurophysiol 73:333-346. Medline

Rothstein JD, Martin L, Levey AI, Dykes-Hoberg M, Jin L, Wu D, Nash N, Kuncl RW (1994) Localization of neuronal and glial glutamate transporters. Neuron 13:713-725. CrossRef Medline

Rothstein JD, Patel S, Regan MR, Haenggeli C, Huang YH, Bergles DE, Jin L, Dykes Hoberg M, Vidensky S, Chung DS, Toan SV, Bruijn LI, Su ZZ, Gupta P, Fisher PB (2005) Beta-lactam antibiotics offer neuroprotection by increasing glutamate transporter expression. Nature 433:73-77. CrossRef Medline 
Scimemi A, Tian H, Diamond JS (2009) Neuronal transporters regulate glutamate clearance, NMDA receptor activation, and synaptic plasticity in the hippocampus. J Neurosci 29:14581-14595. CrossRef Medline

Shih PY, Savtchenko LP, Kamasawa N, Dembitskaya Y, McHugh TJ, Rusakov DA, Shigemoto R, Semyanov A (2013) Retrograde synaptic signaling mediated by $\mathrm{K}^{+}$efflux through postsynaptic NMDA receptors. Cell Rep 5:941-951. CrossRef Medline

Shimamoto K, Sakai R, Takaoka K, Yumoto N, Nakajima T, Amara SG, Shigeri Y (2004) Characterization of novel L-threo-beta-benzyloxyaspartate derivatives, potent blockers of the glutamate transporters. Mol Pharmacol 65: 1008-1015. CrossRef Medline

Spacek J (1985) Three-dimensional analysis of dendritic spines: III. Glial sheath. Anat Embryol (Berl) 171:245-252. CrossRef Medline

Svensson L, Zhang J, Johannessen K, Engel JA (1994) Effect of local infusion of glutamate analogues into the nucleus accumbens of rats: an electrochemical and behavioural study. Brain Res 643:155-161. CrossRef Medline

Tanaka K, Watase K, Manabe T, Yamada K, Watanabe M, Takahashi K, Iwama H, Nishikawa T, Ichihara N, Kikuchi T, Okuyama S, Kawashima N, Hori S, Takimoto M, Wada K (1997) Epilepsy and exacerbation of brain injury in mice lacking the glutamate transporter GLT-1. Science 276:1699-1702. CrossRef Medline

Wadiche JI, Tzingounis AV, Jahr CE (2006) Intrinsic kinetics determine the time course of neuronal synaptic transporter currents. Proc Natl Acad Sci U S A 103:1083-1087. CrossRef Medline

Williams K (1993) Ifenprodil discriminates subtypes of the N-methyl-Daspartate receptor: selectivity and mechanisms at recombinant heteromeric receptors. Mol Pharmacol 44:851-859. Medline 